\title{
Research on Safety Factor of Important Slope of Extra Height Dam
}

\author{
Bin $\mathrm{Li}^{123, \mathrm{~A}}$, Maoji $\mathrm{Li}^{123}$ \\ ${ }^{1}$ Tianjin Port Engineering Institute Ltd. of CCCC First Harbor Engineering Company Ltd., Tianjin, \\ 30222 China; \\ 2.Key laboratory of port geotechnical engineering, ministry of communications, PRC Tianjin, 30222 \\ China; \\ ${ }^{3}$ Key laboratory of port geotechnical engineering of Tianjin, Tianjin, 30222 China \\ aemail:lee_binbin@163.com
}

\begin{abstract}
Keywords: slope; ratio safety margin; risk standard; safety factor;
Abstract: The slope stability allowed reliable index is 4.2 in specification of rockfill dam for $200 \mathrm{~m}$ height, critical slope safety factor of stability is 1.3 , but there is not a fitted safety standard for rockfill dam of more than $200 \mathrm{~m}$ height and critical slope of this project. Summarizes the failure probability, safety standards and puts forward an acceptable risk criteria of slope (failure probability), ratio safety margin is a method to verify the rationality of risk standards and risk control level of safety factor of slope stability. Allowed reliable index for the slope of rockfill dam with extra height is 4.2 and 3.95, and the corresponding safety factor of the slope stability is 1.35 and 1.4 , according to the practical engineering to verify reasonability of safety factor and allowed reliable index of rockfill dam with extra height. The safety control standard of the slope of rockfill dam with extra height should to be improved.
\end{abstract}

\section{Introductions}

With the development of construction technology of embankment dams, a group of more than $200 \mathrm{~m}$ height embankment dam has been built, such as Nuozhadu, Shuangjiangkou, Shuibuya and so on. The exist design specification of embankment dam only be used for the embankment dam whose height below 200m, The design of high embankment dam are based on previous experience or design specification of embankment dam only be used for the embankment dam whose slopes stability analysis does not have a uniform safety standard. However, a safety factor for high embankment dam slopes according to design specification of embankment dam with below $200 \mathrm{~m}$ height at high risk which is not appropriated and need to be solved, so a safety factor of slopes stability of embankment dam with extra height should be urgent need.

Embankment dam with extra height slope stability safety evaluation is a critical technical issues when the design and construction of embankment dams, the design specifications (SL274-2001) stipulates clearly that the nonlinear strength index be used to stability analysis, an average of small value of shear strength index be used to calculate slopes stability safety factor of grade $\square$ embankment dam, the result is greater than 1.5 under normal conditions; conservancy and hydropower project standard for reliability design (GB50199—94) provisions that reliable indicator is 4.2 when the Grade $\square$ dam occurred the Grade $\square$ damage, corresponding to the probability of failure is $1.33 \times 10^{-5}$. So the probability of failure of embankment dam with extra height should be less than the embankment dam with below $200 \mathrm{~m}$ height, another words, allowed reliable indicator of slope stability for embankment dam with extra height should not be less than 4.2.

For more than $200 \mathrm{~m}$ high earthfill dams now does not have a widely recognized allowed reliability index, but the failure probability of earthfill dams should not higher than the current 200 $\mathrm{m}$ class the failure probability of earth dam, IWHR put forwards slope stability failure probability 10-8 and slope stability allowed reliability index is 4.7 for more than $250 \mathrm{~m}$ height earth dam,

The height between $200 \mathrm{~m}$ to $250 \mathrm{~m}$ earth dam, slope failure probability $5 \times 10-8$, and allowed reliable index is 4.45. According to this reliable indicators of water resources and hydropower engineering, this paper study on safety standard of the high earthfill dams, and to validate the rationality of the proposed standard. 


\section{Risk Control Standard of Slope}

The extra height dams are constructing, the problem of security and stability of high slope is coming with it. The slope specification of Water conservancy and hydropower stipulated safety level of slope according to the level of the hydraulic structures to determinate, but a first-class engineering safety standard is unlimited, so slope safety standards of high dam which influence the safe of the engineering follow the first-class engineering standard to design safety slope is not reasonable. Another, the current slope design specification of the earth dam is not a widely accepted allowed reliable indicator. In this paper, from the viewpoint of statistics and engineering safety, on the slope failure probability are discussed.

In the field of engineering risk analysis and risk management, allowed risk standard usually is described as a probability that the life of person will be destroyed in every single year. This is an easy operation description of risk index. In China there is no clear slope risk standard, the overseas related research started early, more mature. Risk figure related materials of other countries and regions slope are collected, on the basis of this information to research slope risk control standard of China.

According to the ministry of land and resources issued in $2004 \sim 2013$ national geological disasters, according to the landslide disaster of geological disasters by the proportion of the total number of casualties calculated landslide casualties every year in our country, the significant individual landslide disasters have the detailed record need separate statistics. Roughly counted casualties in this decade caused by landslide disaster, statistical data as shown in table 1.

Table 1 China's annual landslide disaster casualties' statistical table

\begin{tabular}{ccc} 
year & casualties & risk $\left(10^{-5}\right)$ \\
\hline 2004 & 735 & 0.2 \\
2005 & 486 & 0.6 \\
2006 & 970 & 1.0 \\
2007 & 635 & 0.3 \\
2008 & 757 & 0.2 \\
2009 & 394 & 0.6 \\
2010 & 647 & 0.6 \\
2011 & 302 & 0.8 \\
2012 & 380 & 0.8 \\
2013 & 476 & 0.6 \\
\hline
\end{tabular}

From table 1 can be seen, nearly 10 years in China, the landslide disaster caused casualties every year is about $400 \sim 1000$, through a risk figure access to the risk of slope in 10-5 10-6. International risk analysis of slope expert professor Fell, through analysis of the risk of various industries, for passive risk-drivers, allowed risk should be less than 10-6 in annual terms, no larger than 10-5. For the slope engineering, Fell on the detailed review and analysis of the risk of slope in theory and practice experience, put forward as shown in table 2 control standards.

Table 2 Professor Fell advises slope risk analysis control standards

\begin{tabular}{cl}
\hline situation & \multicolumn{2}{c}{ allowed risk in annual } \\
\hline \multirow{2}{*}{ Established slope } & $10^{-4}$, the nearby people \\
& $10^{-6}$, the general population \\
\cline { 2 - 2 } New slope & $10^{-5}$, The nearby people \\
& $10^{-6}$, the general population \\
\hline
\end{tabular}

Risk criteria and location of slope region also has a certain relationship with the level of economic development, through the statistics, in general, different countries and regions have the probability of death all around 10-6 caused by disasters, as shown in table 3 . 
Table 3 Recent years, the average number of deaths and the annual probability of countries

\begin{tabular}{lccc}
\hline \multicolumn{1}{c}{ country } & $\begin{array}{c}\text { annual } \\
\text { death }\end{array}$ & $\begin{array}{c}\text { toll } \\
\text { population }\end{array}$ & landslide in personnel death probability \\
\hline Japan & 150 & $1.5 \times 10^{8}$ & $1 / 1 \times 10^{-6}$ \\
South Korea & 56 & $0.7 \times 10^{8}$ & $1 / 1 \times 10^{-6}$ \\
The United States & $25 \sim 50$ & $2.5 \times 10^{8}$ & $1 / 1 \sim 2 \times 10^{-6}$ \\
Australia & $<1$ & $1.7 \times 10^{7}$ & $1 / 17 \times 10^{-6}$ \\
Canada & 5 & $0.3 \times 10^{7}$ & $1 / 6 \times 10^{-6}$ \\
Hong Kong $(1984 \sim 1984)$ & 1 & $5.8 \times 10^{6}$ & $1 / 6 \times 10^{-6}$ \\
\hline
\end{tabular}

According to the analysis of slope of countries and regions, reference to risk standard of some foreign countries and China's economic development level, for the natural slope and slope of China water resources and hydropower engineering, put forward the acceptable risk of slope in China should be set as the failure probability in annual between 10-5 10-6. For the slope of the importance, the bigger, and the influence after the destruction, set the level of the failure probability of slope in annual terms as 10-6 can be widely accepted.

Chen zuyu suggested that the risk calculated by one year as Py and risk calculated by many years as $\mathrm{P}$ have the following relations.

$$
P \mathrm{y}=\frac{P}{T} \times \frac{N_{\mathrm{d}}}{T}
$$

The $\mathrm{T}$ for the life, Nd to design a base year.

Calculation follow as (1), often difficult to determine the life of a slope, as a conservative approach, assumes that $\mathrm{T}=\mathrm{Nd}$, the type can be expressed as:

$$
P_{\mathrm{y}}=\frac{P}{N_{\mathrm{d}}}
$$

In water resources and hydropower engineering, the design base year for 100 of first-class, the slope failure probability can be calculated for 10-4 by type (2), looking up the failure probability and reliability index table, the level of the slope reliability index is 3.7.

\section{Safety Standard Calculation of Slope}

China Institute of Water Conservancy and Hydropower institute proposed ratio safety margin method which is a measure between the safety standards and the design requirements of the building standard. Defined safety factor method of ratio safety margin $\eta_{R}$ and traditional methods ratio safety margin $\eta_{F}$ are calculated as follows:

$$
\begin{gathered}
\eta_{R}=\left(\beta-\beta_{a}\right) \sigma_{F}+1 \\
\eta_{F}=\frac{F}{F_{a}}
\end{gathered}
$$

Under the provision of the reasonable safety factor $F_{a}$ premise, reliability Methods of the ratio safety margin $\eta_{R}$ has a better ability to insinuate $\eta_{F}$.under any condition, can get $\eta_{R} \approx \eta_{F}$. So, it should be known that $F$ and $\beta$ at same risk control level which can be used as important theoretical references for preparation of specification working.

Factor safety standard of slope stability with extra height, which be determined by fitting coefficient of ratio safety margin. Calculate ratio safety margin of songta, nuozhadu and jingping hydropower station dam spillway slope with reliability index 3.95and 4.2, respectively different section forms to calculate the ratio safety margin with safety factor method and reliability method, and linear regression, if fitting slope approximation is 1 , safety factor and reliability index at the same level of risk control.

3.1 The Height between $200 \mathrm{~m}$ to $250 \mathrm{~m}$ Earth Dam. Using the ratio safety margin theory, in the case of allowed reliable indicator is 3.95 , calculation ratio safety margin of reliability method, using different safety coefficient standard $1.35,1.4$, and 1.45 to calculation ratio safety margin of 
safety factor method, and carries on the linear regression. Results are shown in figure1.

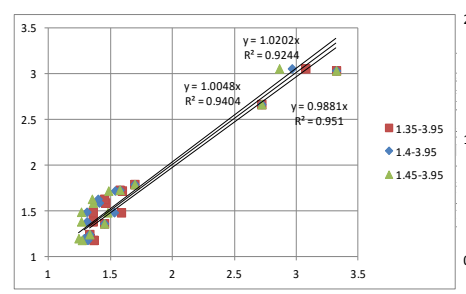

a、 Songta

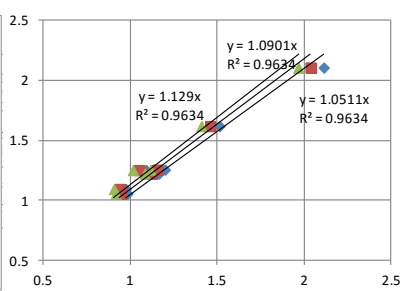

b、 Nuozhadu

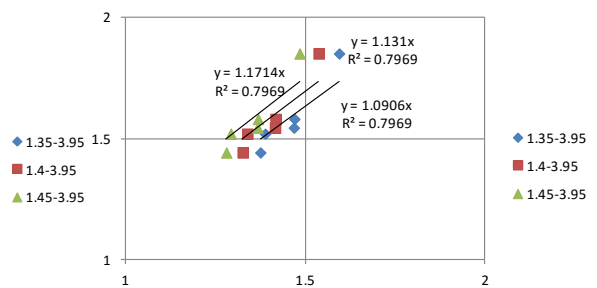

c、 Jinping

Fig. 1 hydropower station slope $\eta_{R}-\eta_{F}$ correlation diagram

Fitting slope ratio of safety coefficient standard 1.35 and the slope reliability index 3.95 is closing to 1 , the highest correlation coefficient, the results are shown that safety coefficient standard 1.35 and reliability index 3.95 of slope engineering instance have the same safety margin. Slope stability safety coefficient1.35 and reliability index 3.95 belong to the same level of risk control.

3.2 More than $250 \mathrm{~m}$ Height Earth Dam. Do as section 2.1, using the ratio safety margin theory, in the case of allowed reliable indicator is 4.2 , calculation ratio safety margin of reliability method, using different safety coefficient standard 1.4, 1.5, and 1.6 to calculation ratio safety margin of safety factor method, and carries on the linear regression.

Fitting line ratio of Slope stability safety coefficient standard 1.4 and the slope reliability index 4.2 is closing to 1 , the highest correlation coefficient; the results are shown that safety coefficient standard 1.4 and reliability index 4.2 of slope engineering instance have the same safety margin. Slope stability safety coefficient 1.4 and reliability index 4.2 belong to the same level of risk control.

\section{Conclusion}

Based on the method of ratio safety margin, considering the influence of parameters variability, computing the ratio safety margin of safety factor method and reliability method, the results shown that when the safety factor is 1.3 , the traditional method of the ratio safety margin, and allowed reliability index is 3.7, the reliability method of the ratio safety margin, the results shown ratio of slope of linear regression fitting is 1 , both at the same level of security.

The height between $200 \mathrm{~m}$ to $250 \mathrm{~m}$ earth dam, the acceptable failure probability is $5 \times 10-7$, allowed reliable indicator 3.95for important high slope at the same risk control level; The acceptable failure probability is 10-7, allowed reliable indicator 4.2 for important high slope of more than $250 \mathrm{~m}$ height earth dam at the same risk control level.

By the calculation of ratio safety margin of three different engineering slopes of the height between $200 \mathrm{~m}$ to $250 \mathrm{~m}$ earth dam and more than $250 \mathrm{~m}$ height earth dam , the corresponding safety coefficient are 1.35 and 1.4. Failure probability, allowed reliable indicator and minimum safety coefficient at the same risk control level.

\section{Reference}

[1] Specification for design of rolled earth rock dam.(DL/T5395-2007) Beijing : China Electric Power Press, 2009

[2] Specification for design of rolled earth rock dam.(SL274-2001) Beijing : China Water Power press, 2002

[3] USNRC. Safety Goals for the Operation of Nuclear Power Plants. Federal Register, 1982, 47: 7023.

[4] CHEN Zu-yu. Soil slope stability analysis - Principles and methods [M], Beijing China Water Power press, 2003:181-196

[5] CHEN Zu-yu, CHEN Li-hong, Sun Ping. An investigation on the allowable factors of safety in slope stability analysis using nonlinear strength parameters[J] . Hydropower, 2004, 30(2): 
17-20.

[6] CHEN Li-hong, CHEN Zu-yu. Influence of nonlinear strength characteristics of rockfill on the stability of high earth rockfill dam[J]. Rock and soil mechanics, 2007, 28(9): 1807-1810.

[7] CHEN Zu-yu, XU Jia-cheng, SUN Ping, gravity sliding stability reliability analysis: (一) the relative safety factor method [J],Journal of Hydroelectric Engineering, 2012,1(3) :167-178

[8] CHEN Zu-yu, XU Jia-cheng, SUN Ping equality, dam stability against sliding reliability analysis: a reasonable value (II) Strength Index and sub-factors [J], Journal of Hydroelectric Engineering, 2012,31 (3): $160-1167$

[9] Specification for design of water conservancy and Hydropower Engineering Slope (SL386-2007) , Beijing: China Water Power press,2007

[10] Unified standard for reliability design of water conservancy and hydropower engineering structure (GB50199-1994),Beijing: China Planning Press, 1994

[11] Fell. R, Landslide risk assessment and acceptable risk[J], Australian-China Landslide Seminar, 1993,2(18): 1-42. 